\title{
An Exercise In Linking Ethics In The Classroom To The Real World
}

Dennis R. Laker, Widener University, USA

Gregory P. Cermignano, Widener University, USA

\begin{abstract}
As academics we are faced with a series of challenges in teaching about ethics in the classroom. We are expected to engage our students and help them become more proactive in the process of learning; link the classroom with the "real world"; and provide them the opportunity to develop both career-related skills and the opportunity to explore potential careers if they are to have a successful professional future. The following exercise addresses these challenges. The exercise involves the student identifying significant, discipline-based ethical issues; and contacting and discussing these issues with a professional in their career field. The exercise also includes a reflective component and an opportunity for the students to share their findings with their peers. This exercise helps to increase the relevance of the ethical material presented in class by putting this knowledge in the specific professional context to which the student aspires, and results in bridging the "classroom" with the "real world." A description and rationale for the exercise; materials; student feedback and benefits; and suggestions for faculty are included.
\end{abstract}

Keywords: Ethics, teaching ethics, exercise, networking, pre-socialization, real world

\section{INTRODUCTION}

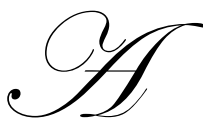

$\mathrm{s}$ academicians we are faced with a series of challenges in teaching about ethics in the classroom. We are expected to engage our students and make them active participants in their education. We are expected to create a realistic link between the classroom and their future professional life. Finally, we are encouraged to provide them with the opportunity to develop both the career-related skills and engage them in the career exploration that is necessary for a successful and productive professional future. The exercise described in this paper presents one way to address each of these challenges in teaching about understanding and practicing professional ethics. The exercise involves identifying significant ethical issues that are discipline-based and contacting and discussing these issues with a professional in one's chosen field. The exercise has a reflective component that allows students to integrate the content of the classroom, their own research on discipline-based ethical issues, and their discussion with a professional in their field in a written summary of their experience. They are also encouraged to share their experiences with each other in class discussions.

\section{OBJECTIVES OF THE EXERCISE}

There are five objectives of the exercise described in this paper. The first is to help students better understand ethics and ethical dilemmas. The second is to help them identify significant ethical dilemmas or issues in their chosen profession. The third is to actively engage them in the learning process. The fourth is to provide an exercise that will offer them an anticipatory socialization experience. The fifth is to help the student acquire the skills necessary to develop and maintain professional relationships.

More than 200 students have participated in this exercise over the past two years.

The summary of this article will illustrate how each of these objectives was achieved through this exercise by examining the written comments of these students. 
The first objective of this exercise is no different than most exercises in ethics. That objective is to better understand ethics and the implications of ethical dilemmas, ethical conflicts, and the various frameworks that can be used to analyze and resolve these dilemmas or conflicts. This objective includes three parts: A. the ability to recognize and understand ethical dilemmas; B. the ability to identify the relevant stakeholders in each dilemma and their perspective, and; $\mathrm{C}$. how to apply various ethical frameworks to analyze and potentially resolve each dilemma. These objectives are normally the focus of most ethics exercises. It is at this point that our exercise goes beyond these other exercises.

The second objective of this exercise is to bring greater realism into the classroom. This exercise attempts to integrate the ethics material discussed in the classroom with the "real world" and thus validate the value of the classroom experience. Although frequently far from the case, most college students make a clear distinction between their current experience in college and their future experiences in the "real world." This exercise creates an opportunity for students to integrate their classroom experience with interactions with others in their chosen professional field. A major focus of this objective is for students to identify the ethical dilemmas faced by professionals in their field and then discuss them with such a professional. Discussing ethical issues with working professionals adds greatly to the realism and importance that student's then attribute to the subject of ethics.

The third objective is to more actively engage the student in the learning process. In many instances, the student is a mere passive recipient of the knowledge that is dispensed in the classroom. The professor lectures and the student take notes, or the professor makes assignments and the student goes on the Internet and searches for the answer. This exercise forces a student to be active and self-directed rather than a passive participant in the learning process. Active learning consists of behaviors that engage the student in the learning process. Auster \& Wylie (2006) have emphasized the increasing expectation of management educators to create a learning environment that “...engage[s], inspire[s], and motivate[s] students to learn both the content and the skills that they need" (p. 333). Their recommendation emphasizes the role of action learning in the classroom and its primary focus of transforming students into active participants in the acquisition of knowledge (Ellerman, 1999).

The fourth objective is for the exercise to serve as an anticipatory socialization experience for students by putting them in a professional environment in order to discuss the ethical concerns of their field with a working professional. The ideal of creating opportunities for anticipatory socialization helps to better prepare students for the professional fields that they have chosen by providing those students with a more realistic understanding of what to expect once they enter a specific profession. With the exception of internships and c o-ops, most students do not get a true picture of what it is to be a professional within a specific field until they become formally employed. Anticipatory socialization should also emphasize the importance of career exploration, the development of job search-related skills, continued professional development, and career management. Each of these should be embedded into the learning activities and opportunities that we assign or provide in class (Laker \& Laker, 2007; Laker, 2002; Lyon \& Kirby, 2000). Just like future learning builds on the content, we should provide opportunities in the class both for skill development and the development/enhancement of self-efficacy (Bandura 1997; 1986) as it relates to those skills.

The fifth objective is to have our students start to acquire skills in developing and maintaining professional relationships (networking). Most college students suffer under the illusion that developing professional relationships is something they do once they graduate from college and the skills that are necessary to do so will just materialize. This exercise provides the opportunity to start developing these networking skills and creates a viable opportunity for students to contact a professional in their field and then maintain that relationship. The importance of networking has been well documented in a variety of areas: in seeking employment; obtaining needed resources; identifying mentors; acquiring advancement; fostering professional development and so on.

The fourth and fifth objectives also address other concerns that many of us have as academics. The present authors as well as some others have strongly advocated that career-related exercises should play a logical and necessary role in the classroom (Laker, 2002; 2007; Lyon \& Kirby, 2000). The present exercise provides the opportunity for students to start developing both the career-related skills of networking and of career exploration necessary for a successful and productive professional life. 


\section{THE STEPS TO THIS EXERCISE}

There are five steps to this exercise. The first is for the student to identify their professional field. In some instances students are interested in a variety of areas and they are encouraged to choose the area that most interests them at this point in time. However, in some instances they have chosen to interview others in more than one professional area. The second is to identify a series of ethical issues that they would like to discuss. This is often done through the reading of trade publications in a particular professional area, reading the newspaper, or reviewing what are the "hot" topics in the news at that point in time. Trade publications for a particular professional area can be acquired by contacting professional associations and organizations that represent the professions that the students are interested in or by going through one's library's data base. An exercise involving Googling professional organizations and identifying these trade publications has been developed by the first author (Laker, 2008). The third step involves identifying the relevant stakeholders, issues and values in conflict. The fourth step involves identifying and ultimately contacting a professional to interview. The fifth step involves summarizing the exercise.

In the first step students identify the professional field that they plan to enter upon graduation. I have used this exercise with students in the areas of Accounting, Finance, Sports Management, General Management, and Human Resources, but I (first author) believe that this exercise can be adapted for almost any professional area. The students then identify the ethical concerns or dilemmas that they will be discussing. For each ethical concern, the student identifies the significance of the issue, and the various, relevant stakeholders. For each stakeholder, the student identifies the values in conflict both within each stakeholder and between stakeholders. The goal of this part of the exercise is to help the student identify the different perspectives or interpretations of the same situation and the various values that are in conflict. This helps to increase the students' awareness of the complexity and interrelatedness of ethical dilemmas.

In the second step, they identify three ethical concerns /dilemmas that are extremely significant in their professional area. Ethical issues are primarily chosen because of their significance within that profession. In other instances, a student chooses a particular issue based upon a personal or some other professional interest. For most students, significance can be determined in a variety of ways: its prevalence or frequency in the field; the number of professionals or companies involved; the degree of impact, amount of money involved; number of stakeholders involved; length of time it has been going on; amount of publicity, notoriety; specific people involved; or their personal or professional interest; an increasing or decreasing trend in their field i.e., Is the issue becoming more of a problem? Or is it getting worse? In each instance, the students explain the reason for their choice and provide supporting evidence of the significance. I frequently encourage students to contact professional organizations in the career of interest and then review trade publications in these areas to help in identifying relevant ethical issues and dilemmas (Laker, 2008).

As mentioned previously, I have used this exercise with a wide range of students representing the academic fields of: Accounting (public, auditing); Management Information Systems; Finance (personal, investment, corporate); Marketing (sales, advertising); Fashion Design.

Accounting/ Public/ Auditing. Examples from Accounting have included: the certification of false financial statements, "cooking the books", tax evasion, money laundering, embezzlement and creation of fake invoices, the destruction of documents and evidence, whistle blowing, and the backdating of stock options.

Management Information Systems. Examples in the field of Management Information Systems have included: the illegal downloading of material that is copyrighted (copyright infringement), illegal advertising on the web, identify theft, privacy issues and the inappropriate use of information, and the negligent storage of information.

Finance. In the area of Finance, students have selected and discussed: insider training, churning (trading stocks and bonds unnecessarily merely to create additional fees and service charges); various forms of conflict of interests, deceptive loan practices, issues of privacy, identify theft and embezzlement. 
Marketing/Advertising/Sales. Examples in this area have included: deceptive advertising (weight loss), advertising to children (fast food, soft drinks, toys), stereotyping in advertising, bribery, and the inappropriate targeting of minors.

Fashion Design. This included the use of fur, the impact on the environment (sustainable fibers; i.e., use of cotton), sweat shops and providing a living wage.

Once the ethical issues and dilemmas are identified, the third step involves the students identifying the relevant stakeholders in the conflict, and what values are in conflict for each stakeholder and between stakeholders. These first three steps are very important in helping the student better understand and organize their thoughts concerning their areas of interest.

The fourth step involves the student identifying a professional in their field with whom they wish to discuss these ethical issues. I routinely ask each student who they will discuss these conflicts with and why they chose this individual. Students are given a great deal of freedom in whom they choose to interview for this exercise. The primary criterion for choosing an individual is that he or she is in the professional area and is knowledgeable of the ethical issues confronting the profession. But beyond that there are a number of secondary criteria that have proved beneficial in guiding the students' choice. Some examples are: a relative working in their particular area of interest; someone who works for a company that they are interested in working for in the future; an individual that is routinely confronted by these types of ethical dilemmas in a professional capacity; or someone they greatly respect. A more complete list of these additional selection criteria can be obtained from the first author. Once the student has identified the relevant criteria, students identify people who match those criteria. Potential contacts might include friends, alumni, parents of other students, members of local professional organizations, people known by their professors, and so on (Laker, 2002). In order to facilitate their networking skills, it is often best to have the students identify their contacts without the direct assistance of the faculty.

Through the experiences of the students, I have found that it is best to break the contacting process down into the following four steps:

- $\quad$ Identifying the individual you wish to contact. Students use their previously determined criteria to identify someone to interview. When in doubt, I usually suggest that students ask others to help them identify potential contacts. The following prompts are almost always successful. "Who do you know that is like this?" or "Do you know anyone who works in this area ___ and does this ___ ?" or even "Do you know anyone who would know someone like this?" I have also suggested that students Google professional organizations and identify members of local affiliates. Through these websites they can often obtain the phone number, e-mail addresses, or the web site of the members in their local areas. I have also suggested that students go where people who fit the professional profile might meet (i.e., trade shows, conferences, professional meetings). There are innumerable ways students can identify and locate the types of individuals that they may interview.

- $\quad$ Persuading one to make the contact. I try to emphasize to the students that they will not always be successful in making successful contact with a particular individual. A variety of reasons may prevent the student from making a specific contact. It is my experience that in almost all instances, the reasons have nothing to do with the students themselves (Laker, 2002; Laker \& Laker, 2007). I emphasize to the student that it is a "numbers game" - the more people they try to connect with, the more people they will successfully interview.

- Making the contact. If time is available, it is recommended that students make the initial contact through a letter or email. Most students find this approach much less threatening and it usually results in a positive response from the contact. This initial message should include the following: who they are, a brief statement of why they are contacting the individual, how they obtained the person's name, and an explanation of why the student specifically identified them to contact for their participation in the interview. Students should also include when and how they will next contact the person to set up an interview (i.e., "I'll call you on the morning of" or "Monday of next week").

- $\quad$ Conducting the interview. I usually encourage the student to visit the individual at his or her place work if it is at all possible. Such an experience is extremely beneficial for the student in formulating what it is to be in a professional context in his or her future career. Based upon my experience, it is extremely 
important that the student is prepared to interview the contact at the next opportunity. Occasionally, some professionals have actually requested the interview questions ahead of time and the student should be prepared for this possibility. In completing the interview, students should thank their contacts verbally and then follow up with a letter or email reiterating their appreciation for taking the time and effort to talk with them.

The fifth step is to have students summarize what they have learned from this exercise. Students prepare a final paper that outlines how they have performed each of the five steps of the exercise and the conclusions they have drawn. Students should use this summary to reflect upon their experience and discuss what they have learned about the ethical concerns and dilemmas in their anticipated profession as well as to what extent their beliefs about that profession have in any changed. At this time, we also ask each student to evaluate the exercise by answering the following four questions:

1. What difficulties did you have in completing this exercise?

2. How did you resolve these difficulties?

3. What do you consider the benefits of this exercise?

4. What do you consider the disadvantages of this exercise?

It is through the students' answers to these four questions and their summaries of their experiences that we have found the exercise to be most beneficial.

\section{BENEFITS OF THE EXERCISE}

Through our experiences we've found this to be a novel way of introducing students to the concept of ethics and ethical dilemmas. As one can tell by both our previously discussed experiences in the classroom and in the following comments that students have made about the exercise, there was a great variety of ethical issues and concerns that were raised as a result of this exercise. One of the critical objectives of this exercise that was clearly reflected in the comments was the student's perception of the professional relevance of their subsequent experience in exploring the ethical issues that are involved in their prospective career field.

The student's comments also demonstrated their increasing self-efficacy as it relates to their ability to develop and potentially maintain professional relationships. Many students were initially hesitant in their efforts to contact professionals in their field, but through the observations of others and discussions of each student's experiences in the classroom, students found themselves better able to meet the challenges of initiating such interactions and in carrying them through to completion. As mentioned previously, such networking skills have been routinely associated with success in both seeking employment and in more successfully managing one's career. Although we have no quantitative data on how much better our students are in understanding the ethical issues confronted in their field, their comments in evaluating their exercise experience strongly indicates that they were both more interested in the topic of ethics and were much more conversant on the subject during class discussion. As several writers have emphasized in the past, students today need to be much more proactive in their educational experience and greater self-directed learning will be the template for future.

The difficulties, benefits and objectives of this exercise are illustrated in the following student comments.

\section{SELECTIVE STUDENT WRITTEN COMMENTS}

"I am always nervous to go out and talk to people at first, but I am beginning to realize that that is stupid and it is a very important thing I must do."

"This helped me see what our future jobs would be like in terms of ethical decisions. It opens our eyes to the real world we are going to enter."

"I was aware of some of the issues I discussed, but I didn't realize how dangerous some of them can be."

"I was unsure of whom to interview but after making a few calls I found out my new neighbor was in marketing." 
"I had difficulty in deciding on whom to contact and have a conversation with. I really can not hold a conversation for to long and was nervous about that. I realized I just had to step up to the plate and stop worrying about little things."

"This was relatively simple to complete due to the people I knew and who they knew so I could talk with them about the ethical dilemmas."

"My primary difficulty.... was finding free time in both my and my contacts' busy schedules to discuss..."

"I found my ability to contact people was greater than I ever expected."

"I learned that it is not as hard as I thought. I got stuck thinking there are these barriers between me and other people and I realized that is not the case at all."

"I learned that my mother is a vital source to make contacts in the future. She works as a high executive in a large corporation."

"Professionals are more willing than students may think to offer assistance."

"I learned that you have to take risks and contact people you may not know to create future opportunities."

"Make it mandatory for students to contact someone they do not know. I found it difficult to contact people I didn't know but I feel this exercise helped me and enabled me to make a good contact."

"This exercise forced us to be more proactive in our future careers. This is important because these are things we would not typically do ourselves. I for one, now see why these types of exercises are helpful."

"Going from taking notes in the classroom to actually being around professionals is quite motivational."

"I met one of my contacts as we planned the $50^{\text {th }}$ anniversary of my social organization, and the other is an alumnus of my fraternity."

"I talked to an accountant - I chose this individual because he comes into the bank every Friday to cash his check. He is very friendly, drives a nice car, has a nice pay check and seems fairly successful."

\section{RECOMMENDATIONS AND SUGGESTIONS FOR FACULTY}

There are really two separate, yet related parts to this exercise. The first is to identify and then research the various ethical issues that are significant in one's professional field. As previously described, this first step is rather straight-forward and usually does not present much of a challenge for most students. The second part of this exercise involves identifying, initiating contact with a professional in their field, and then having a conversation about ethics with them. This represents the most challenging aspect of this exercise and yet typically proves to be the most beneficial to the student. This is especially true in terms of the students' pre-socialization into their prospective careers. Because this second part of the exercise is the one students find most challenging it is the primary focus of the next section on recommendations and suggestions for faculty.

A traditional evaluation of this exercise is difficult. We found it extremely difficult to evaluate the completion of this exercise in the traditional sense of looking for a correct or desired response. Instead, we focused on whether and to what extent the student completed each of the various steps of the exercise. All five steps should be part of the evaluation process. Judging the efficacy or benefits of this exercise should not be restricted to only whether there is a demonstrable impact on their understanding of ethical principles. The success of this exercise is not that they can merely regurgitate ethical issues per se, but that they understand and appreciate the implications of ethical concerns and dilemmas in their future profession. Many students, upon completion of this exercise, come to the conclusion that they have not had a very clear understanding of the field in which they were majoring and have changed their mind concerning their interest in that particular area. Although at times disheartening, this can be a blessing in disguise in terms of someone changing career direction before it becomes difficult to do so. 
This exercise is designed to be for at least a half of a semester. A shorter time frame seems to be considerably less beneficial for the students. The exercise requires a great deal of the students' time. This time also provides the students with an opportunity to contact various professionals by using their school breaks and vacations to interview people near their homes or elsewhere.

Feedback is extremely important. It is best to provide feedback and input to students at each step of the exercise. The first author typically reviews the ethical issues that they have identified and discusses them in class. The faculty then starts to help them create a process for identifying who they might contact. Their professors, alumni office, people they might have interned with, older students, neighbors, contacts through professional organizations, etc. have all proved helpful in this identification process.

This is not an exercise of convenience. Students should identify specific individuals or types of people that they would get the most out of speaking with. Too frequently students want to interview only those people that they already know or who are physically or emotionally convenient. The criteria for interviewing someone should not be who would be the easiest to interview, but rather, who would provide the student with a valuable perspective or insight into a particular career-related ethical issue or dilemma. The student usually needs to go beyond the personal, professional or organizational worlds with which they are most familiar. The professor can help the student in this respect by presenting stories and illustrations of students who were successful in completing this exercise or some other exercise that involved reaching out to professionals in their field. Such illustrations are especially necessary in helping students develop greater self-efficacy (Bandura, 1986; 1997) and thus go beyond their comfort zone.

I have usually required students to only interview one individual, but some students have suggested that I should require them to interview more people in order to get a broader and possibly better understanding of the ethical issues in a particular profession.

One needs to provide the opportunity for weekly or biweekly discussion of the exercise. I usually assign this exercise early in the semester and I have the students discuss weekly their experiences and problems in completing the exercise. I usually put the students in a dyad or triad to discuss their experiences. As a class, I then have each student summarize his or her experience and his or her comments using the board or flip chart. Students vicariously learn from each other (see Bandura's discussion on learning through modeling, 1986; 1997) and I have found that frequently one student's success can go a long way in encouraging another student to try something different. During this time the faculty can also provide any necessary guidance or support to a student or students, or present a pertinent story or illustration that would serve both to provide guidance in what to do and motivation to do it.

Class discussion and debriefing. It is extremely important to emphasize to the students that this is a learning experience that for many of them is extremely challenging. They are not only learning material on ethics and ethical dilemmas, but something about themselves as well. This exercise serves as an opportunity for pre-socialization into their chosen profession and for many it is the first direct experience that they have with their profession. It also enriches their skills of developing and possibly maintaining professional relationships. This exercise helps the student identify and practice strategies or approaches for successfully contacting and maintaining professional relationships with others in the future. The first author places a significant emphasis on Bandura's $(1986 ; 1997)$ work on self-efficacy theory in this regard. The students' self-efficacy or their belief in their ability to do something successfully is extremely important in this exercise. As mentioned previously, the most challenging task that most students face is their effort to identify and then subsequently contact a professional in their field. The use of stories emphasizing persistence and effort leading to success as well as how other students overcame difficulties in this exercise and were eventually successful all help to model a more proactive, high self-efficacy orientation towards this and similar exercises (Bandura, 1986; 1997). Students should be encouraged to maintain the connections that they have made through this exercise.

\section{SUMMARY}

This ethics exercise is a tool designed to assist students in better understanding the complexity of ethical issues and dilemmas. The exercise asks the student to link their educational experience with their future career through the pre-socialization activity of contacting professionals in the field that they hope to enter. Although we 
have no quantitative data on how much better our students understand the ethical issues confronted by their field, their comments in evaluating this exercise, strongly indicate that they were more interested in the topic of ethics and were found to be much more conversant on the subject during class discussion. As several writers have emphasized in the past, students today need to be much more proactive in seeking their educational experience, and greater selfdirected learning will be the template for future professional development.

There are four additional objectives of this exercise: to actively engage the student in the learning process; to help them become proactive in their learning; provide them with an anticipatory socialization experience in their chosen profession; and finally, help the student acquire the skills necessary for developing and maintaining professional relationships. It is clear by the students' comments that these objectives were achieved.

One final comment. It is also our contention that the responsibility of the faculty should go beyond the students' academic preparation in the classroom. Faculty should provide students with opportunities and assignments that facilitate career exploration, the development of job search skills, continued professional development, and career management. These should be a logical extension of the activities, opportunities and exercises that are assigned in the classroom. The type of experience that results from this exercise increases the student's perceived relevance of the academic material presented in class by putting this knowledge in a specific professional context. Their experience highlights the relevance of this material by bridging the "classroom" with the "real world" of the professional environment.

\section{AUTHOR INFORMATION}

Dennis R. Laker is an Associate Professor in Human Resources and Management in the School of Business Administration at Widener University in Chester, Pennsylvania, USA. He received his Ph.D. from the University of Illinois in Champaign-Urbana. His publications have appeared in Human Resource Development Quarterly, Journal of Employment Counseling, International Journal of Human Resources: Development and Management and Journal of College Teaching \& Learning, Journal of Management Education as well as many other academic and practitioner-oriented publications. His research interests are primarily in the area of training, self-directed learning, and career exploration and development. He was the recipient of the 2006 Distinguished Teaching Award for the School of Business Administration

Gregory P. Cermignano, JD, CMA is an Associate Professor of Accounting and Business Law at Widener University. Professor Cermignano has been the coordinator of the undergraduate business law program and teaches both graduate and undergraduate law courses. He was the recipient of the 2000 and 2004 Distinguished Teaching Award for the School of Business Administration. He is currently involved in doing research which deals with the connection between accounting and the law

\section{REFERENCES}

1. Auster, E.R. \& Wylie, K.K. (2006). Creating active learning in the classroom: A systematic approach. Journal of Management Education, 30(2) 333-353.

2. Bandura, A. (1986). Social foundations of thought and action. Englewood Cliffs, New Jersey: PrenticeHall, Inc.).

3. Bandura A. (1997). Self-efficacy the exercise of control. New York: W.H. Freeman and Company.

4. Ellerman, D. P. (1999). Global institutions: Transforming international development agencies into learning organizations. The Academy of Management Executive, 13, 25-35.

5. Laker, D.R. (2008). The role of professional organizations in professional development. Unpublished manuscript.

6. Laker, D. R. \& Laker, R. (2007). The five year resume: A career planning exercise. Journal of Management Education. 31(1), 128-141.

7. $\quad$ Laker, D.R.. (2002). The Career Wheel: An Exercise for Exploring and Validating One's Career Choices." Journal of Employment Counseling. 39, 61-72.

8. Lyon, D. W, \& Kirby, E. G. (2000). The career planning essay. Journal of Management Education, 24, 276287. 